\title{
EXPERIMENTAL LIFE-HISTORY EVOLUTION: SELECTION ON THE ALLOCATION TO SEXUAL REPRODUCTION AND ITS PLASTICITY IN A CLONAL PLANT
}

\author{
Mark van Kleunen, ${ }^{1,2,3}$ Markus Fischer, ${ }^{1,4}$ And Bernhard Schmid ${ }^{1,5}$ \\ ${ }^{1}$ Institut für Umweltwissenschaften, University of Zurich, Winterthurerstrasse 190, CH-8057 Zurich, Switzerland \\ ${ }^{2}$ E-mail:vkleunen@uwinst.unizh.ch \\ ${ }^{4}$ E-mail: fischerm@uwinst.unizh.c \\ 5E-mail: bschmid@uwinst.unizh.ch
}

\begin{abstract}
Allocation to sexual reproduction is an important life-history trait in clonal plants. Different selection pressures between competitive and competition-free environments are likely to result in the evolution of specialized genotypes and to maintain genetic variation in reproductive allocation. Moreover, selection may also result in the evolution of plastic allocation strategies. The necessary prerequisite for evolution, heritable genetic variation, can best be studied with selection experiments. Starting from a base population of 102 replicated genotypes of the clonal herb Ranunculus reptans, we imposed selection on the proportion of flowering rosettes in the absence of competition (base population: mean $=0.391$, broad-sense heritability $=0.307)$. We also selected on the plasticity in this trait in response to competition with a naturally coexisting grass in a parallel experiment (base population: 14\% lower mean in the presence of competition, broad-sense heritability $=0.072$ ). After two generations of bidirectional selection, the proportion of flowering rosettes was $26 \%$ higher in the high line than in the low line (realized heritability \pm SE $=$ $0.205 \pm 0.017$ ). Moreover, genotypes of the high line had $11 \%$ fewer carpels per flower, a $22 \%$ lower proportion of rooted rosettes, and a 39\% smaller average distance between rosettes within a clone. In the second experiment, we found no significant responses to selection for high and low plasticity in the proportion of flowering rosettes (realized heritability $\pm \mathrm{SE}=-0.002 \pm 0.013$ ). Our study indicates a high heritability and potential for further evolution of the proportion of flowering rosettes in R. reptans, but not for its plasticity, which may have been fixed by past evolution at its current level. Moreover, our results demonstrate strong genetic correlations between allocation to sexual reproduction and other clonal life-history characteristics.
\end{abstract}

Key words. Clonal growth, evolution, genetic correlation, plasticity, Ranunculus reptans, reproductive allocation, selection experiment.

Most evolutionary theory is based on sexually reproducing unitary organisms (Sackville Hamilton et al. 1987; Tuomi and Vuarisalo 1989; Schmid 1990), although many organisms and especially the ones with modular growth, such as plants, have the possibility to reproduce asexually (Salisbury 1942; Klimeš et al. 1997). The balance between sexual and vegetative reproduction may have major consequences for evolution in these organisms due to effects on demography (Abrahamson 1980; Eriksson 1986), population genetic structure (McLellan et al. 1997; Chung and Epperson 1999; Ceplitis 2001), dispersal (Stöcklin 1999; Winkler and Fischer 2002), and metapopulation processes (Piquot et al. 1998; Gabriel and Bürger 2000).

Because of a limited availability of resources or meristems, there may be a trade-off between both modes of reproduction (Harper 1977; Watson 1984). Whereas sexual reproduction may allow escape from poor environmental conditions, vegetative reproduction may be beneficial as a means to remain in benign environments (Williams 1975; Abrahamson 1980; Gardner and Mangel 1999). Moreover, sexual reproduction may be selected at the metapopulation level to support colonization of new sites and vegetative reproduction at the population level to support population persistence (Olivieri et al. 1995; Piquot et al. 1998).

Natural selection may only result in evolutionary change of reproductive allocation if there is heritable genetic vari-

\footnotetext{
${ }^{3}$ Present address: Department of Forest Science, The University of British Columbia, 2424 Main Mall, Vancouver, British Columbia V6T 1Z4, Canada.
}

ation. Studies on quantitative genetic variation in reproductive allocation of clonal plants are scarce and report only broad-sense heritabilities (Fischer and van Kleunen 2001). To estimate narrow-sense heritabilities, which would demonstrate additive genetic variation, more sophisticated quantitative genetic approaches are required (Falconer and Mackay 1996). The most direct way to test whether reproductive allocation can evolve is to perform an artificial selection experiment and to estimate the realized heritability from the response to selection.

Even if there is heritable variation in reproductive allocation of clonal plants, its evolution may be constrained if it cannot evolve independently of other important traits, which may lead to opposing selection pressures (Lande and Arnold 1983). In clonal plants, negative genetic correlations have been reported between the allocation to sexual and vegetative reproduction (Geber et al. 1992; Prati and Schmid 2000; Ronsheim and Bever 2000). Furthermore, sexual reproduction may be a more important dispersal mechanism for clonal plants with a compact growth form than for ones with a spreading growth form (Sackville Hamilton et al. 1987), which suggests that selection pressures for a compact growth form and a high sexual reproductive allocation may coincide. Therefore, it is likely that sexual reproductive allocation does not evolve independently of other clonal lifehistory traits.

Variation in reproductive allocation is not only a consequence of differences among genotypes but also of their plastic responses to the environment. If there is spatial or temporal heterogeneity at a scale relevant to the plant, plasticity 
itself may be under selection and can evolve if there is genetic variation for it (Bradshaw 1965). Studies on the response to selection on plasticity, however, are scarce. Some studies have selected indirectly for reduced plasticity (i.e., for canalization) by crossing individuals that have high trait values in an environment that induces low trait values with individuals that have low trait values in an environment that induces high trait values (Waddington and Robertson 1966; Thompson and Kauffman Rook 1988). Other studies have selected directly on plasticity values based on family means in two different environments (Waddington 1960; Kindred 1965; Druger 1967; Brumpton et al. 1977; Jinks et al. 1977; Hillesheim and Stearns 1991; Scheiner and Lyman 1991). Clonal plants are well suited for such selection experiments because vegetative reproduction allows determination of the plasticity of individual genotypes by growing replicates in different environments. So far, however, there have not been studies that selected experimentally on plasticity in clonal plants.

We investigated heritable genetic variation in the proportion of flowering rosettes and its plasticity in the stoloniferous herb Ranunculus reptans. This species grows naturally in habitats that vary in the intensity of interspecific competition along shores of lakes and rivers and changes its reproductive allocation plastically in response to competition (Prati and Schmid 2000). Although seedling recruitment was observed within established populations (Prati and Peintinger 2000), its demographic importance relative to clonal recruitment is unclear. However, in a greenhouse study Prati and Schmid (2000) found that $R$. reptans plants from competitive microsites invested relatively more in sexual reproduction, whereas plants from competition-free microhabitats invested more heavily in vegetative reproduction. This suggests that selection pressures on $R$. reptans differ between microhabitats.

Starting from a base population of 614 plants representing 102 genotypes grown in the presence or absence of competition with the naturally coexisting grass Agrostis stolonifera, we performed two bidirectional selection experiments for two generations; (1) on the proportion of flowering rosettes in a competition-free environment; and (2) on plasticity of this trait in response to competition. We measured the response to selection of the selected traits and of other important traits related to reproduction (proportion of rooted rosettes, number of carpels per flower), size (number of rosettes), and growth form (clonal spread, leaf and internode lengths).

We asked the following specific questions: Is there heritable genetic variation in the proportion of flowering rosettes of $R$. reptans and in its plasticity in response to competition? Can these traits evolve independently of other clonal lifehistory and morphological traits?

\section{Materials And Methods}

\section{Study Species}

The stoloniferous, rosette-forming herb $R$. reptans L. (Ranunculaceae) has a circumpolar distribution, mainly in the temperate to boreal-subarctic zones of Europe, Asia, and North America (Hess et al. 1980). The species has a strict habitat requirement and in central Europe only grows on periodically inundated lakeshores with low vegetation cover. Today, most central European populations are found around Lake Constance on the borders of Austria, Germany, and Switzerland (latitude: $47^{\circ} 40^{\prime} \mathrm{N}$, longitude: $9^{\circ} 20^{\prime} \mathrm{E}$ ). Within these populations, there is a consistent gradient between microhabitats. Plants growing close to the winter water level of the lake experience an average summer-inundation period of 150 days and little competition with other species. Plants growing about $30 \mathrm{~cm}$ higher and $10 \mathrm{~m}$ further away from the lake experience an average summer-inundation period of 80 days and competition with grasses, most commonly $A$. stolonifera (Prati and Schmid 2000).

Rosettes of $R$. reptans may have one to 20 leaves. Leaf blades are $10-50 \mathrm{~mm}$ long and $1-5 \mathrm{~mm}$ wide and gradually narrow into the petioles. Rosettes form stolon branches from meristems in the axils of leaves. Stolons grow sympodially and consist of rooted and unrooted rosettes connected by thin (0.5-2.0 mm diameter) stolon internodes with a length of 3$5 \mathrm{~cm}$. Stolon branches can grow as far as $10-20 \mathrm{~cm}$ within a growing season. Each rosette may produce one flower, which does not exclude the formation of roots, and one or more side branches (i.e., sexual and clonal reproduction are not mutually exclusive; Prati and Peintinger 2000). The production of stolon branches is interrupted by the summer inundation period, during which stolon internodes decay (D. Prati, pers. comm.). The flowers are partly self-incompatible, slightly protrandrous, and insect pollinated (Prati and Peintinger 2000).

\section{Plant Material and the Base Generation}

To broadly sample potential genetic variation in $R$. reptans, we collected 104 plants from 14 populations around Lake Constance in 1995 and 1997. Randomly amplified polymorphic DNA (RAPD) analysis revealed that the 104 plants represented 102 different genotypes (Fischer et al. 2000b). The plants were propagated repeatedly, and vegetative offspring were kept in a plant room at $25^{\circ} \mathrm{C}$ with $16 \mathrm{~h}$ of artificial light in $40 \times 70 \mathrm{~cm}$ trays filled with a $4: 1$ mixture of sand and compost. Plants representing all genotypes were cultivated for at least eight months before the experiment began.

The selection experiments were performed in the same plant room as the precultivation. For the plants of the base generation, we filled $7831 \times 44 \mathrm{~cm}$ trays with a soil mixture of the same composition as during precultivation and covered it with a thin layer of gravel. On 14 November 1997, we randomly assigned three rosettes of each of the 102 genotypes (two genotypes were represented by six rosettes) to the eight planting positions in each of 39 trays (totaling 312 plants), with the limitation that rosettes planted to the same tray belonged to different genotypes.

We did the same for the other set of 39 trays into which we additionally sowed A. stolonifera as competitor. Agrostis stolonifera formed a dense matrix with about 1 plant $/ \mathrm{cm}^{2}$, which is comparable to densities found in the natural habitat of $R$. reptans at Lake Constance. Within trays, interference among $R$. reptans individuals was probably weak because their root systems are relatively small, which makes overlap of rooting zones of the originally planted rosettes unlikely, and because $R$. reptans plants impose hardly any shading. 
Plants were watered every second day, and trays were assigned to new random positions in the plant room weekly. These experimental conditions were maintained throughout the selection experiments. After eight weeks, we counted the total number of rosettes and the number of flowers on each originally planted rosette, and calculated the proportion of flowering rosettes.

\section{Selection on the Proportion of Flowering Rosettes}

To start the selection lines for a low and a high proportion of flowering rosettes, we selected from the base generation the 20 genotypes with the lowest mean values and the 20 genotypes with the highest ones in the competition-free environment. We selected on genotypic values and not on individual values because replicated measurements of genotypes give a more precise estimation of the heritability (Falconer and Mackay 1996) and because we wanted to have a selection procedure that is similar to the one in the selection experiment on plasticity in the proportion of flowering rosettes (see next section). The 20 genotypes used as parents for the low (L) line and the 20 genotypes used as parents for the high $(\mathrm{H})$ line came from 11 and 11 different populations, respectively (the deviation from equal representation of the 14 populations in both selection lines was not significant in a chi-squared test, $\chi_{13}^{2}=15.1, P=0.302$ ). This indicates that we did not recreate pre-existing genetic differentiation between populations in this selection experiment. For each selection line, we cross-pollinated each of the selected genotypes with two of the other selected ones. From these crosses for 40 full-sib families 17 were successful, but we could increase the number of full-sib families for the next generation by adding seeds from crosses of the selection experiment on plasticity in the proportion of flowering rosettes and from two other selection experiments on growth form and its plasticity (M. Fischer, M. van Kleunen, and B. Schmid, unpubl. data) that started from the same base generation and had some of the selected parents in common with the lines of this experiment. We incubated all seeds in a solution of $2 \mathrm{mg} \cdot \mathrm{ml}^{-1}$ gibberellic acid for five days to break dormancy. Then we sowed the seeds, and finally we vegetatively propagated the offspring.

On 28 January 1999, we planted 46 rosettes belonging to 26 genotypes of 16 full-sib families of the $\mathrm{L}$ line and 56 rosettes belonging to 26 genotypes of 10 full-sib families of the $\mathrm{H}$ line as the first offspring generation. After eight weeks, we selected of each selection line the eight genotypes with the most extreme trait values as parents for the second offspring generation. We crossed the selected genotypes of each line in two separate full-diallel designs. Because $R$. reptans is partly self-incompatible, this would have resulted in $2 \times$ $28=56$ full-sib families, each with two reciprocal paternalmaternal parent combinations. The crosses were successful for 33 full-sib families.

On 14 February 2000, we planted 131 rosettes belonging to 46 genotypes of 15 full-sib families of the L line and 143 rosettes belonging to 49 genotypes of 18 full-sib families of the $\mathrm{H}$ line as the second offspring generation. As control for the direction of selection, we also planted two or three ro- settes of each of 15 randomly chosen genotypes of the base generation.

\section{Selection on Plasticity in the Proportion of Flowering Rosettes}

The procedure and number of genotypes selected as parents for the consecutive generations of the lines in the selection experiment on plasticity in the proportion of flowering rosettes was the same as in the one on the mean proportion of flowering rosettes. Phenotypic plasticity was defined as the change in the average phenotype expressed by a genotype in different environments (Via 1987). Although the magnitude of a plastic response may be the same for a genotype that increases the proportion of flowering rosettes in response to competition and one that decreases it, their plasticities clearly differ in direction (i.e., the slopes of their reaction norms differ). Therefore, we used signed values of plasticity, which were calculated for each genotype by subtracting the genotypic mean value in the competitive environment from the one in the competition-free environment. For convenience, we refer to positive and negative values as high and low plasticity, although the choice to calculate plasticity in this direction was subjective. The 20 genotypes used as parents for the low-plasticity (LP) line and the 20 genotypes used as parents for the high-plasticity (HP) line came from 11 and 12 different populations, respectively (the deviation from equal representation of the 14 populations in both selection lines was not significant in a chi-square test, $\chi_{13}^{2}=14.8, P$ $=0.320$ ). This indicates that we did not recreate pre-existing genetic differentiation between populations in this selection experiment.

In the first offspring generation, for the line selected for a low plasticity in the proportion of flowering rosettes (LP line) we planted 86 rosettes belonging to 29 genotypes of 15 fullsib families, and for the line selected for a high plasticity in the proportion of flowering rosettes (HP line) we planted 142 rosettes belonging to 39 genotypes of 15 full-sib families. In the second offspring generation, for the LP line we planted 233 rosettes belonging to 43 genotypes of 17 full-sib families, and for the HP line we planted 234 rosettes belonging to 42 genotypes of 17 full-sib families. In each generation, half of the replicates of each genotype were grown without competition and the other half with competition with A. stolonifera. In the second offspring generation, we additionally planted two or three rosettes of each of 15 randomly chosen genotypes of the base generation into the competition-free trays and two or three rosettes into the ones with competition as a control for the direction of selection.

\section{Measurements}

Eight weeks after the start of each generation, in addition to the number of rosettes and flowering rosettes, we measured the number of rooted rosettes on each originally planted rosette as a measure of vegetative reproduction. Moreover, as measures of plant morphology, we measured the spatial spread of the clone (i.e., distance between the two most distant rosettes of a clone), the length of the longest leaf, and the length of the first three internodes on the largest stolon branch on each originally planted rosette. As measures of the 
relative allocation to sexual and vegetative reproduction and of growth form, we calculated the proportion of flowering rosettes, proportion of rooted rosettes, and spatial spread of the clone divided by the number of rosettes (i.e., spread per rosette), respectively. For the second offspring generation, we also counted the number of carpels of the first flower on the largest stolon branch of each originally planted rosette to test for a potential trade-off between the proportion of flowering rosettes and the number of carpels or ovules (one ovule per carpel) per flower.

\section{Analyses}

For the calculation of the broad-sense heritability of the proportion of flowering rosettes in the base generation, we estimated variance components (VC) with restricted maximum-likelihood (REML) analyses of variance (Patterson and Thompson 1971) with the statistical software Genstat (Lawes Agricultural Trust, IACR, Rothamsted; Payne et al. 1993). The VC for genotypes represents $100 \%$ genetic (additive and nonadditive) and potential maternal genetic and environmental variation. The VC for the residual represents $100 \%$ environmental variation between individuals within genotypes. Thus, the broad-sense heritability, $H^{2}$, was calculated as

$$
H^{2}=\mathrm{VC}_{\text {genotype }} /\left(\mathrm{VC}_{\text {genotype }}+\mathrm{VC}_{\text {residual }}\right) .
$$

Similarly, we calculated the broad-sense heritability of plasticity in the proportion of flowering rosettes as

$$
H^{2}=\frac{\mathrm{VC}_{\text {genotype } \times \text { competition }}}{\left(\mathrm{VC}_{\text {genotype }}+\mathrm{VC}_{\text {genotype } \times \text { competition }}+\mathrm{VC}_{\text {residual }}\right)},
$$

where $\mathrm{VC}_{\text {genotype } \times \text { competition }}$ is the variance component for the genotype-by-competition interaction. We used mean trait values of genotypes in the competition-free environment of the base generation to calculate genetic correlations between different traits.

The response to selection $(R)$ is proportional to the narrowsense heritability, $h^{2}$, and to the selection differential $(S$; Falconer and Mackay 1996): $R=h^{2} \times S$, where $R$ is the difference in mean phenotypic value of the offspring genotypes and the mean phenotypic value of the population from which the parent genotypes were selected and $S$ is the difference in mean phenotypic value of parents and the population mean from which the parents were selected. Accordingly, we estimated the realized heritabilities for the proportion of flowering rosettes and its plasticity after two generations of selection as the coefficients of regression of the response to selection after each generation of selection on the cumulative selection differential before each generation of selection (Falconer and Mackay 1996). The selection differentials were calculated for each generation and each line separately as the differences between the average value of genotypes in that line and the average value of the genotypes that were selected as parents for the next generation. Because not all selected parents contributed equally to the next generation, selection differentials were weighted according to the number of offspring genotypes per parent (Falconer and Mackay 1996). Then, the selection differentials of the low and high lines were summed and subsequently they were summed after each generation. The realized responses to selection were calculated as the differences in the mean values between the low and high lines after each generation of selection.

Because in the offspring generations the numbers of genotypes per full-sib family and the numbers of full-sib families per line were unbalanced, we analyzed the data with REML analysis of variance for each generation separately. The effect of selection for low and high values was considered fixed and was tested with the Wald test statistic, which has an asymptotic chi-squared distribution (Dobson 1990). Variations among full-sib families and between reciprocals within full-sib families (second generation) were considered as random effects. Because variance components of reciprocals were small or zero in the REML analysis (indicating that genotypes did not perform differentially as male or female partners in diallel crosses), we removed this effect from the final model. The variation among full-sib families was tested with a likelihood-ratio test (Morrell 1998), which tests the change in deviance after removing the factor seed families from the model. The change in deviance is approximately chi-squared distributed (Littell et al. 1996). Data from the control plants were not included in the analyses of the second offspring generation. The number of rosettes, the proportion of rooted rosettes, and the spread per rosette were $\log _{10^{-}}$ transformed to achieve normality and homoscedasticity.

We tested whether differences (if present) in the proportion of flowering rosettes between the competitive and competition-free environment and between the selection lines either were a consequence of plants being at different positions along the same allometric trajectory (given by number of flowers $=\alpha$ [number of rosettes $]^{\beta}$ ), or a consequence of differences in the allometric relationships between the number of flowers and rosettes (Weiner 1988; Jasienski and Bazzaz 1999). To this end we regressed the number of flowers on the number of rosettes after $\log _{10}$-transformation, yielding

$$
\left.\log _{10} \text { (no. of flowers }\right)=\log _{10}(\alpha)+\beta \log _{10} \text { (no. of rosettes). }
$$

To test whether the mean number of flowers and the regression slopes (allometric exponents) differed between lines in the selection experiment on the proportion of flowering rosettes and between competitive and competition-free environments in the base population, we used an analyses of variance in which the number of rosettes was included as covariate. In the case of an isometric relationship, that is, if $\beta=1$, the intercept $\log (\alpha)$ can be used to estimate the allocation to flowers, that is $\alpha$ (Schmid and Weiner 1993).

\section{RESULTS}

\section{Selection on the Proportion of Flowering Rosettes}

Heritabilities and direct response to selection. - In the base generation, the proportion of flowering rosettes was on average 0.391 in the competition-free environment (Fig. 1A), and there was significant variation among genotypes in the proportion of flowering rosettes $\left(F_{101,208}=2.35, P<0.001\right)$. The corresponding broad-sense heritability of the proportion flowering rosettes was 0.307 . The weighted means of the genotypes selected as parents for the first offspring generation of the $\mathrm{H}$ and $\mathrm{L}$ lines were 0.537 and 0.280 , respectively. In 
A

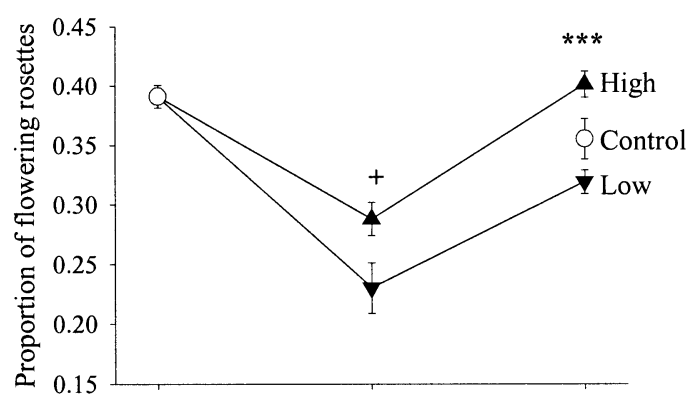

C

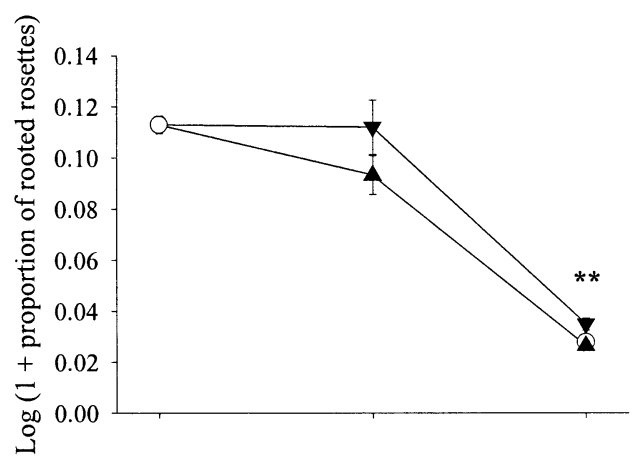

E

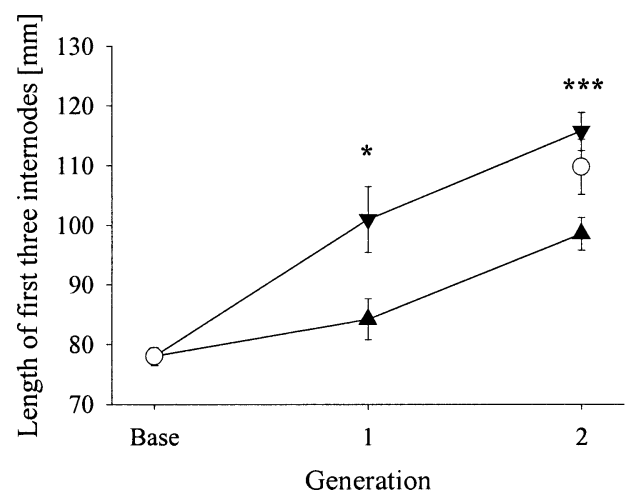

B

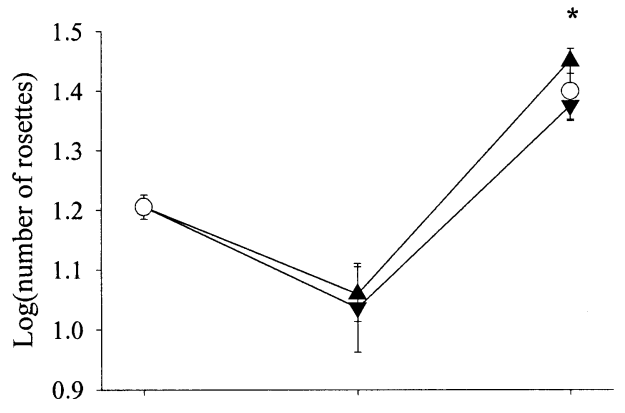

D

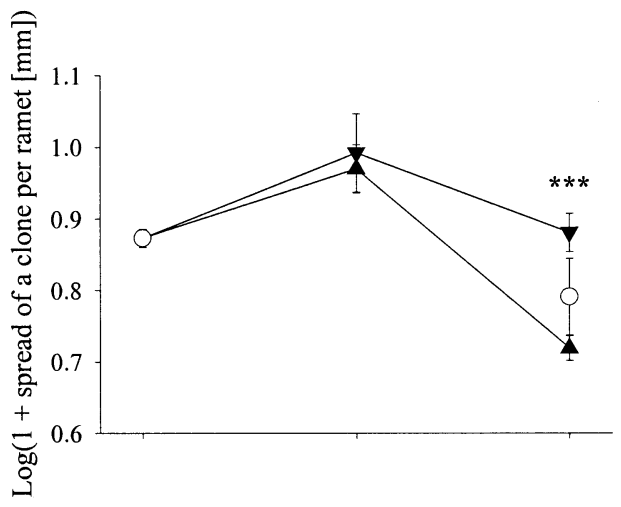

F

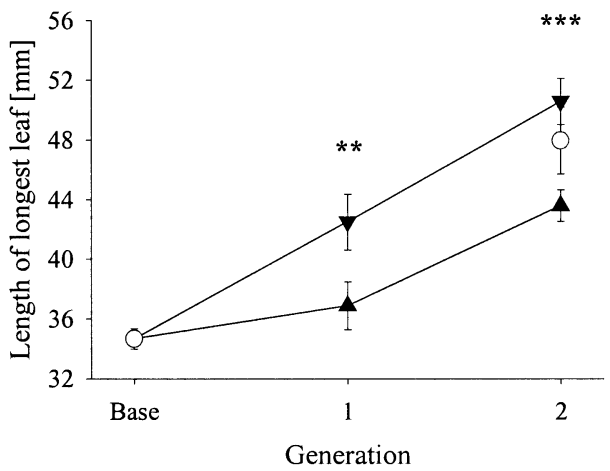

FIG. 1. Response to two generations of bidirectional selection on the proportion of flowering rosettes in (A) the proportion of flowering rosettes, (B) the number of rosettes, (C) the proportion of rooted rosettes, (D) the spatial spread per rosette, (E) the length of the first three internodes, and (F) the length of the longest leaf of Ranunculus reptans. Error bars represent \pm 1 SE of the mean. $\nabla$, line selected for a low proportion of flowering rosettes; $\boldsymbol{\Lambda}$, line selected for a high proportion of flowering; $\bigcirc$, control plants. Significance levels (see Tables 1, 2): ${ }^{+} P<0.1, * P<0.05, * * P<0.01$, *** $P<0.001$.

the first offspring generation, genotypes of the $\mathrm{H}$ line had a $25.2 \%$ higher proportion flowering rosettes than genotypes of the L line, although this effect was not quite significant (Table 1). The weighted means of the genotypes that were selected as parents for the second offspring generation of the $\mathrm{H}$ and $\mathrm{L}$ lines were 0.356 and 0.151 , respectively. In the second offspring generation, genotypes of the $\mathrm{H}$ line had a significantly $25.7 \%$ higher proportion of flowering rosettes than genotypes of the L line (Fig. 1A, Table 1). The realized heritability $\pm \mathrm{SE}$ after two generations of selection was 0.205 \pm 0.017 .

The slopes $(\beta)$ of the log-log regression of the number of flowers on number of rosettes were not significantly different for the $\mathrm{L}$ and the $\mathrm{H}$ lines (number of rosettes-by-line interaction in ANCOVA: $F_{1,270}=2.36, P=0.125$; Fig. 2) and not significantly different from one (for $\mathrm{L}$ line: $\beta=1.020$ $\pm 0.034, t_{129}=0.59, P=0.556$; for $\mathrm{H}$ line: $\beta=0.950 \pm$ $\left.0.030, t_{141}=-1.67, P=0.098\right)$. Accordingly, we used the 
TABLE 1. Statistical effects of selection on the proportion of flowering rosettes and associated traits after one and two generations of selection. The table gives Wald test statistics, changes in deviance from restricted maximum-likelihood analyses of variance of effects of the selection line and of variation among seed families in clonal life-history traits (the number of carpels per flower was measured in the second offspring generation only) and morphological traits after one and two generations of the selection on the proportion of flowering rosettes Ranunculus reptans. The effect of the selection line was tested with the Wald test, and the variance among seed families with the change in deviance after removing this factor from the model. Both the Wald test and the change in deviance are chi-squared distributed with 1 df. Significance levels are in parentheses.

\begin{tabular}{|c|c|c|c|c|c|c|c|}
\hline \multirow[b]{2}{*}{ Generation and effect } & \multicolumn{7}{|c|}{ Trait } \\
\hline & $\begin{array}{l}\text { Proportion } \\
\text { of flowering } \\
\text { rosettes }\end{array}$ & $\begin{array}{l}\text { Number of } \\
\text { rosettes }\end{array}$ & $\begin{array}{c}\text { Proportion } \\
\text { of rooted } \\
\text { rosettes }\end{array}$ & $\begin{array}{l}\text { Spatial } \\
\text { spread per } \\
\text { rosette }\end{array}$ & $\begin{array}{l}\text { Length of } \\
\text { first three } \\
\text { internodes }\end{array}$ & $\begin{array}{l}\text { Length of } \\
\text { longest leaf }\end{array}$ & $\begin{array}{l}\text { Number of } \\
\text { carpels per } \\
\text { flower }\end{array}$ \\
\hline Selection line (Wald test) & $3.7(0.054)$ & $0.0(1.000)$ & $1.3(0.254)$ & $0.2(0.655)$ & $5.3(0.021)$ & $10.2(0.001)$ & - \\
\hline Seed family (change in deviance) & $0.9(0.343)$ & $2.6(0.107)$ & $1.0(0.317)$ & $2.0(0.157)$ & $1.0(0.317)$ & $1.0(0.317)$ & - \\
\hline \multicolumn{8}{|l|}{ Second offspring generation } \\
\hline
\end{tabular}

intercepts to estimate the proportion of flowering rosettes $(\alpha)$ : 0.338 for the $\mathrm{H}$ line and 0.512 for the $\mathrm{L}$ line. Because there was no difference in slope between lines, we can take the difference in mean number of flowers (line effect in $\mathrm{AN}$ COVA: $\left.F_{1,270}=7.72, P=0.006\right)$ as an indication that the lines also differed in the intercepts, that is, proportion of flowering rosettes (Schmid and Weiner 1993).

Correlated responses to selection.-In the base generation, the proportion of flowering rosettes correlated positively with the number of rosettes and negatively with the proportion of rooted rosettes and with the spread per rosette among genotypes (Table 2). After one generation of selection, genotypes selected for a high proportion of flowering rosettes also had more rosettes $(5.4 \%)$ and a lower proportion of rooted rosettes $(-18.5 \%)$, spread per rosette $(-5.4 \%)$, internode length $(-16.6 \%)$, and leaf length $(-13.2 \%)$ than genotypes selected for a low proportion of flowering rosettes (Fig. 1BF), although the difference was only significant for internode and leaf length (Table 1). After two generations of selection,

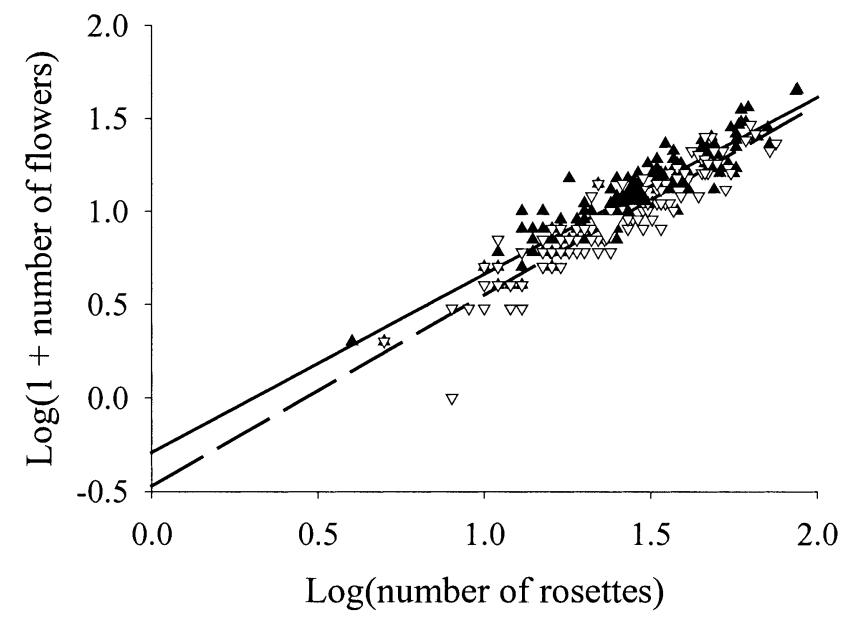

FIG. 2. Allometric relations between the number of flowers and the number of rosettes of lines of Ranunculus reptans selected for a high $(\boldsymbol{\Lambda}$, solid line $)$ and a low $(\nabla$, dashed line) proportion of flowering rosettes for two generations. The slopes of the regression lines were not significantly different between the high and low line, but the means (large symbols) were $(P<0.01)$. these differences were more pronounced and all were significant; genotypes selected for a high proportion of flowering rosettes had more rosettes $(18.9 \%)$ and a lower proportion of rooted rosettes $(-25.4 \%)$, spread per rosette $(-35.8 \%)$, internode length $(-14.8 \%)$, and leaf length $(-13.8 \%)$. Moreover, the number of carpels per flower was lower by $10.5 \%$ among genotypes selected for a high proportion of flowering rosettes (mean $\pm \mathrm{SE}=12.38 \pm 0.39$ ) than in genotypes selected for a low proportion of flowering rosettes (mean \pm $\mathrm{SE}=13.83 \pm 0.37$; Table 1 ). This negative response was smaller than the positive response in the proportion of flowering rosettes, and as a consequence the number of carpels averaged per rosette was higher for the high line (mean \pm $\mathrm{SE}=4.93 \pm 0.18$ ) than for the low line (mean $\pm \mathrm{SE}=4.50$ $\pm 0.18)$, although this effect was not quite significant $\left(\chi_{1}^{2}=\right.$ 2.7, $P=0.100)$.

\section{Selection on Plasticity in the Proportion of Flowering Rosettes}

On average, genotypes in the base generation had a significantly higher proportion of flowering rosettes when they grew in a competition-free environment (mean $\pm \mathrm{SE}=0.391$ $\pm 0.009)$ than in a competitive environment $(0.337 \pm 0.011$; $\left.F_{1,101}=14.24, P<0.001\right)$. Furthermore, the slopes of the log-log regression of number of flowers on number of rosettes were significantly higher for plants in the competition-free environment (number of rosettes-by-competition interaction in ANCOVA: $F_{1,601}=46.60, P<0.001$; Fig. 3 ). The slope of the regression in the competition-free environment was about one $\left(\beta=0.973 \pm 0.023, t_{309}=-1.17, P=0.242\right)$,

TABLE 2. Genotypic correlations $(N=102)$ between the proportion of flowering rosettes and the other clonal life-history traits and morphological traits in the base generation of the selection experiment with Ranunculus reptans. Significance levels are in parentheses.

\begin{tabular}{lc}
\hline \hline \multicolumn{1}{c}{ Trait } & $r$ \\
\hline Number of rosettes & $0.376(<0.001)$ \\
Proportion of rooted rosettes & $-0.417(<0.001)$ \\
Spread per rosette & $-0.382(<0.001)$ \\
Length of first three internodes & $0.096(0.337)$ \\
Length of longest leaf & $0.133(0.183)$ \\
\hline
\end{tabular}




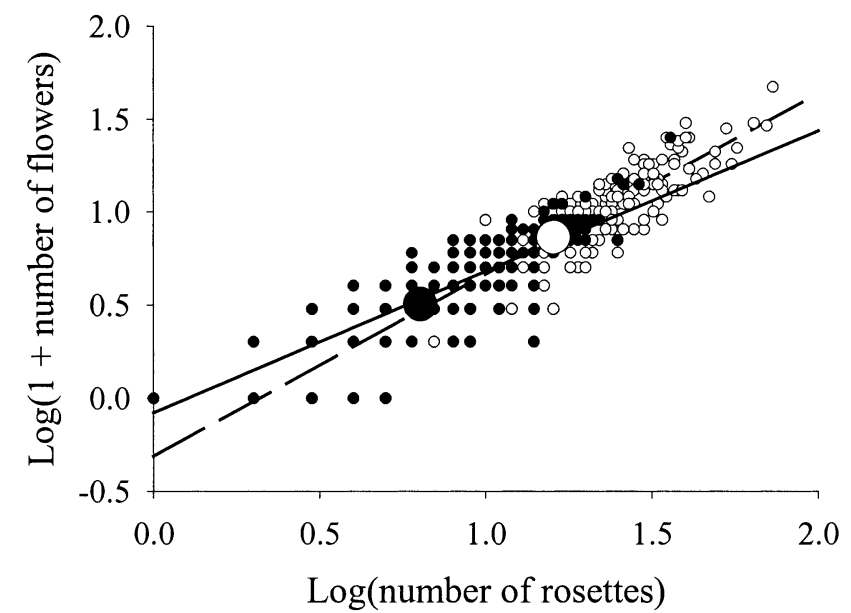

FIG. 3. Allometric relations between the number of flowers and the number of rosettes of plants of the base generation of the selection experiment with Ranunculus reptans grown in the absence $(\bigcirc$, dashed line) and presence $(\bullet$, solid line) of competition. Both the slopes of the regression lines and the means (large symbols) were different between the low and high line (both $P<0.001$ ).

indicating a linear, isometric relation, whereas the slope in the competitive environment was significantly less than one, indicating an allometric relation of decreasing reproductive allocation with increasing plant size $(\beta=0.757 \pm 0.021$, $\left.t_{294}=-11.57, P<0.001\right)$. If the allometric relations within the competition-free and competitive environment hold within each other's data ranges after extrapolation, plants in the competition-free environment had more flowers (competition effect in ANCOVA: $F_{1,578}=31.21, P<0.001 ;$ Fig. 3$)$, yet a lower allocation coefficient $(\alpha=0.490)$ than plants in the competitive environment $(\alpha=0.834)$.

There was significant variation among genotypes in plasticity for the proportion of flowering rosettes $\left(F_{101,401}=1.28\right.$, $P=0.049$ ). The corresponding broad-sense heritability of plasticity in the proportion of flowering rosettes was 0.072 . The weighted means of plasticity of the genotypes selected as parents for the first offspring generation of the PH and PL lines were 0.237 and -0.118 , respectively. There was no significant response to selection after one generation of selection $\left(\chi_{1}^{2}=0.0, P=1.000\right.$ in REML analyses of variance; Fig. 4). The weighted means of plasticity of the genotypes that were subsequently selected as parents for the second offspring generation of the PH- and PL-line were 0.252 and -0.027 , respectively, yet there was still no significant response to selection $\left(\chi_{1}^{2}=0.0, P=1.000 ;\right.$ Fig. 4$)$. The realized heritability \pm SE was $-0.002 \pm 0.013$.

\section{Discussion}

\section{Direct Response to Selection on the Proportion of Flowering Rosettes}

We found a significant difference between the lines selected for a high and low proportion of flowering rosettes, which indicates that allocation to sexual reproduction can evolve in $R$. reptans. Because the base generation was founded with genotypes from 14 different populations around Lake Constance, this result applies to the metapopulation level.

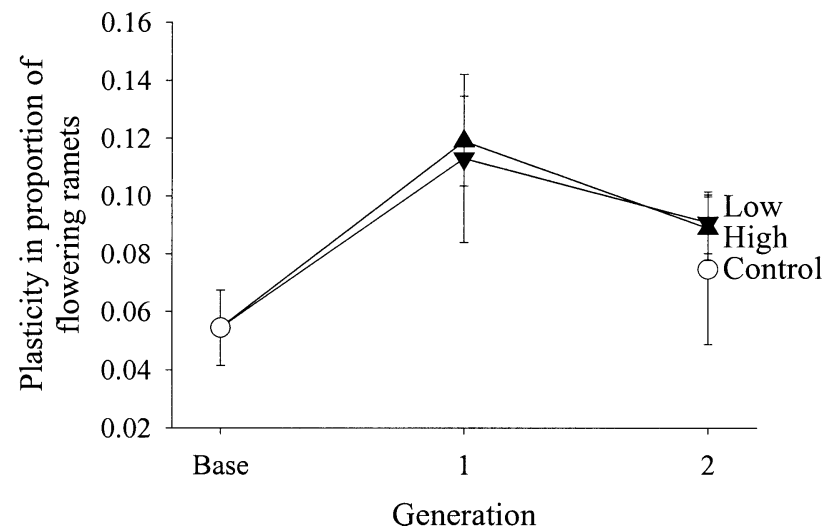

FIG. 4. Response to two generations of bidirectional selection on plasticity in the proportion of flowering rosettes in response to competition for Ranunculus reptans. Error bars represent $\pm 1 \mathrm{SE}$ of the mean. $\boldsymbol{\nabla}$, line selected for a low plasticity in the proportion of flowering rosettes; $\boldsymbol{\Delta}$, line selected for a high plasticity in the proportion of flowering; $\bigcirc$, control plants.

However, because the selected parental genotypes for each line did not come from particular populations (see Materials and Methods), this evolutionary potential does not simply reflect pre-existing population differentiation. There is considerable variation among genotypes within populations (Fischer et al. 2000a), which is partly due to microhabitat heterogeneity, that is, frequently inundated competition-free zones and less-frequently inundated zones with competition by the grass A. stolonifera (Prati and Schmid 2000; van Kleunen et al. 2000a,b; van Kleunen and Fischer 2001).

Genotypes selected for a high proportion of flowering rosettes also produced more rosettes, which may indicate that we indirectly selected for plant size. Sexual reproductive allocation of nonclonal plants or single ramets generally increases with plant size (Weiner 1988; Schmid and Weiner 1993). It has been suggested that such allometric considerations may be less important for organisms with clonal growth in which every module can contribute to different functions (Silvertown 1983; Sebens 1987). However, allometric relations between the number of flowering ramets and the total number of ramets have also been reported for clones of Solidago altissima (Meyer and Schmid 1999). In our experiment, we found that the allometric exponent of the relation between the number of flowers and rosettes was less than one in the presence of competition but equal to one in the absence of competition in the base generation (Fig. 3) and equal to one in the lines selected for a low and high proportion of flowering rosettes for two generations (Fig. 2). While the relation was thus linear for both selection lines, the proportion of flowering rosettes (the constant $\alpha$ in the allometric equation) was lower for the line selected for a low proportion of flowering rosettes, confirming the conclusions derived from the selection response and realized heritability measure, in which no size-correction was applied. Therefore, we conclude that the two lines have evolved different proportions of flowering rosettes.

Although we did not replicate our lines, we had replicate full-sib families within the lines, a situation that more realistically mimics natural selection in a population of inter- 
breeding genotypes in the wild than the use of separate lines would do. We therefore conclude that the observed divergent evolution of trait values in response to selection was very likely due to selection rather than genetic drift. The latter would also be unlikely because the response was in the expected direction and because the control genotypes had values intermediate to the ones of the $\mathrm{H}$ and $\mathrm{L}$ lines. Moreover, in another selection experiment we found that the proportion of flowering rosettes increased when we selected for a compact growth form of $R$. reptans (M. Fischer, M. van Kleunen, and B. Schmid, unpubl. results), which is in accordance with the correlated response in growth form that we found in this experiment.

The realized heritability of the proportion of flowering rosettes was more than half of the broad-sense heritability. Nevertheless, a substantial amount of phenotypic variation among genotypes in the base population must have reflected nonadditive genetic variation or maternal environmental carry-over effects. Our estimate of narrow-sense heritability was based on selection on genotypes. Selection on individuals might have resulted in a slightly smaller estimate (P. H. van Tienderen, pers. comm.; K. Ritland, pers. comm.). However, environmental changes between the generations, as indicated by fluctuations in average trait values (Fig. 1), may also have affected our selection process and thus reduced the estimated realized heritability (Falconer and Mackay 1996). Thus, broad-sense and narrow-sense heritability might have been even closer than concluded from our estimates.

Genetic variation in the proportion of flowering rosettes may be maintained by spatial or temporal heterogeneity between or within natural populations of $R$. reptans. Within populations of $R$. reptans along the shore of Lake Constance, there is a consistent gradient in the occurrence of competitive grasses generated by natural summer inundations (Prati and Peintinger 2000). In previous studies, plants from competitive microhabitats had a higher proportion of flowering rosettes (Prati and Schmid 2000) and increased the vertical angle and specific length of their stolons more in response to competition (van Kleunen and Fischer 2001) than plants from competition-free microhabitats when plants were grown in a common greenhouse environment. This indicates that the gradient in competition within populations may be responsible for the maintenance of genetic variation in the proportion of flowering rosettes and other clonal life-history traits. Other mechanisms that may maintain genetic variation in the proportion of flowering rosettes are genotype-by-environment interactions (i.e., differences in plasticity of the proportion of flowering rosettes between genotypes), mutation-selection balance, and genetic correlations with other traits as a consequence of linkage or pleiotropy (Stearns 1992; McLellan et al. 1997).

\section{Correlated Responses to Selection on the Proportion of Flowering Rosettes}

Although there is a high potential for the evolution of the proportion of flowering rosettes in $R$. reptans, correlated responses of other important traits indicate that this trait may not evolve independently. Selection for an increase in the proportion of flowering rosettes resulted in fewer carpels and ovules (in $R$. reptans there is only one ovule per carpel) per flower. This may also have resulted in fewer anthers per flower as indicated by the positive phenotypic correlation between the number of anthers and carpels per flower, which was found in another experiment with $R$. reptans $(r=0.727$, $P<0.001, N=52$; N. Zimmermann and M. van Kleunen, unpubl. data). However, because the reduction in the number of carpels was smaller than the increase in the proportion of flowering rosettes, the number of carpels averaged per rosette tended to be greater for the high than for the low line. This indicates that overall the allocation to sexual reproduction had increased after selection.

The line selected for a high proportion of flowering rosettes had a lower proportion of rooted rosettes, which is in accordance with the negative genetic correlation between the proportion of flowering rosettes and the proportion of rooted rosettes, which we found in the base generation and that had also been found in a previous study with $R$. reptans (Prati and Schmid 2000). Negative genetic correlations between the allocation to sexual and vegetative reproduction were also found in Eichhornia crassipes (Geber et al. 1992) and Allium vineale (Ronsheim and Bever 2000). A trade-off between sexual and vegetative reproduction may be a consequence of a limited number of meristems available for sexual and vegetative reproductive structures or of a limited amount of resources (Harper 1977; Watson 1984). Because in R. reptans flowers and roots do not develop from the same meristems, the results suggest that the genetic trade-off between modes of reproduction is a consequence of limited resources.

Genotypes selected for a high proportion of flowering rosettes had a more compact growth form (i.e., they had a lower spread per rosette) and shorter internodes and leaves than genotypes selected for a low proportion of flowering rosettes. In a selection experiment on growth form of $R$. reptans, we similarly found that selection for a compact growth form resulted in a higher proportion of flowering rosettes (M. Fischer, M. van Kleunen, and B. Schmid, unpubl. data). This indicates that the proportion of flowering rosettes cannot evolve independently of growth form in $R$. reptans.

Genetic correlations may slow the evolution of sexual reproductive allocation in $R$. reptans and may contribute to the maintenance of genetic variation in this trait (Lande and Arnold 1983). However, when similar selective forces act consistently on two traits, genetic correlations may evolve and result in adaptive trait complexes. For example, it was suggested that a high sexual reproductive allocation may be more important as a dispersal mechanism for clonal plants with a compact growth form than for ones with a spreading one (Sackville Hamilton et al. 1987), which would be in accordance with our results. However, negative genetic correlations between important traits may also have evolved as a consequence of antagonistic pleiotropy, where selection for high values of both traits results in the fixation of alleles that produce positive correlations, leaving only those polymorphisms involving alleles with antagonistic effects (Roff 1996).

\section{Plasticity in the Proportion of Flowering Rosettes and Selection on $\mathrm{It}$}

A higher allocation to sexual reproduction under locally adverse conditions (e.g., under competition) would have the 
advantage that seed dispersal may act as a mechanism to escape from these conditions (Ogden 1974; Abrahamson 1975; 1980; Williams 1975; Gardner and Mangel 1999; van Kleunen et al. 2001). Therefore, the higher proportion of flowering rosettes in the competition-free environment than in the competitive one (only positive plasticity values in Fig. 4) suggests that plasticity in the proportion of flowering rosettes does not represent an adaptive plastic response to competition. However, the comparison of the allometric relations between the number of flowers and rosettes of plants grown in the competition-free and competitive environments (Fig. 3 ) indicates that this result may be confounded by size-dependent reproductive allocation: when plants are small, the proportion of flowering rosettes is higher in the competitive environment than in the competition-free environment, and the reverse occurs when plants are large.

We found limited, but nevertheless significant variation in plasticity among genotypes (i.e., significant variation in the slopes of reaction norms) in the base population. Some genotypes responded to competition by strongly increasing the proportion of flowering rosettes, whereas others showed little change or even a decreased proportion. When we subjected the most extreme genotypes along this continuum (HP line with genotypes showing strong increases and LP line with genotypes showing small increases or even decreases) to bidirectional selection on plasticity, no divergence was obtained after two generations of selection (Fig. 4). This suggests that additive genetic variation in plasticity of reproductive allocation, and thus the potential for its evolution, was low in this population of $R$. reptans. Perhaps selection in the past has depleted all additive genetic variation and led to the fixation of the current level of plasticity. This would, in contrast to the predictions made above, suggest that the current level of plasticity is adaptive. However, the lack of a response to selection of plasticity may be a consequence of the difference between the competition-free and competitive environment in the allometric relation between the number of flowers and rosettes. Due to this difference, plasticity of reproductive allocation depends on the average size of plants and the difference in their size between the two environments. Therefore, it is likely that differences in plasticity between genotypes were inconsistent over the generations, which may have hampered a response to selection.

The low broad-sense heritability of plasticity in the base population and the absence of a response to selection (zero narrow-sense heritability) are in line with the observation that heritabilities of plasticity are generally lower than heritabilities of mean trait values (Scheiner 1993). The only other selection experiment on plasticity in a plant species found a significant heritability of plasticity in flowering time and height in Nicotiana rustica in response to sowing date after two generations of selection (Brumpton et al. 1977). After two more generations of selection, however, only plasticity in height responded, whereas plasticity in flowering time responded in the wrong direction (Jinks et al. 1977). Some experiments with animal species successfully selected on plasticity (Waddington 1960; Kindred 1965; Druger 1967), although it sometimes took several generations before the response became visible (Hillesheim and Stearns 1991; Scheiner and Lyman 1991). It may be that in plants the ge- netic basis for plasticity is lower than in animals because, due to the modular growth of plants, they may respond to environmental heterogeneity by passive growth responses rather than by active plastic responses (Schmid 1990).

\section{ACKNOWLEDGMENTS}

We thank R. Schmid, G. Rutherford-Rauh, A. von Foerster, K. Dräger, M. Friedli, K. Boschi, P. Taxböck, J. Lüstenberger, A. Tchouboukov, F. Fritsche, and T. Pfluger for practical assistance; P. van Tienderen and K. Ritland for stimulating discussions; and A. Hector, C. Eckert, and two anonymous reviewers for valuable comments on an earlier version of the manuscript. We acknowledge financial support by the Swiss National Science Foundation (grant 31-49728.96).

\section{Literature Cited}

Abrahamson, W. G. 1975. Reproductive strategies in dewberries. Ecology 56:721-726.

. 1980. Demography and vegetative reproduction. Pp. 89106 in O. T. Solbrig, eds. Demography and evolution in plant populations. Blackwell Scientific Publications, Oxford, U.K.

Bradshaw, A. D. 1965. Evolutionary significance of phenotypic plasticity in plants. Adv. Genet. 13:115-155.

Brumpton, R. J., H. Boughey, and J. L. Jinks. 1977. Joint selection for both extremes of mean performance and of sensitivity to a macro-environmental variable. I. Family selection. Heredity 38 : 219-226.

Ceplitis, A. 2001. The importance of sexual and asexual reproduction in the recent evolution of Allium vineale. Evolution 55: 1581-1591.

Chung, M. G., and B. K. Epperson. 1999. Spatial genetic structure of clonal and sexual reproduction in populations of Adenophora grandiflor (Campanulaceae). Evolution 53:1068-1078.

Dobson, A. J. 1990. An introduction to generalized linear models. Chapman and Hall, London.

Druger, M. 1967. Selection and the effect of temperature on scutellar bristle number in Drosophila. Genetics 56:39-47.

Eriksson, O. 1986. Survivorship, reproduction and dynamics of ramets of Potentilla anserina on a Baltic seashore meadow. Vegetatio 67:17-25.

Falconer, D. S., and T. F. C. Mackay. 1996. Introduction to quantitative genetics. Longman, Essex, U.K.

Fischer, M., and M. van Kleunen. 2001. On the evolution of clonal plant life histories. Evol. Ecol. 15:565-582.

Fischer, M., M. van Kleunen, and B. Schmid 2000a. Genetic Allee effects on performance, plasticity, and developmental plasticity in a clonal plant. Ecol. Lett. 3:530-539.

Fischer, M., R. Husi, D. Prati, M. Peintinger, M. van Kleunen, and B. Schmid. 2000b. RAPD variation among and within small and large populations of the rare clonal plant Ranunculus reptans (Ranunculaceae). Am. J. Bot. 87:1128-1137.

Gabriel, W., and R. Bürger. 2000. Fixation of clonal lineages under Muller's ratchet. Evolution 54:1116-1125.

Gardner, S. N., and M. Mangel. 1999. Modeling investments in seeds, clonal offspring, and translocation in a clonal plant. Ecology 80:1202-1220.

Geber, M. A., M. A. Watson, and R. Furnish. 1992. Genetic differences in clonal demography in Eichhornia crassipes. J. Ecol. 80:329-341.

Harper, J. L. 1977. The population biology of plants. Academic Press, New York.

Hess, H. E., E. Landolt, and R. Hirzel. 1980. Flora der Schweiz. Vol. 2. Birkhäuser, Basel.

Hillesheim, E., and S. C. Stearns. 1991. The responses of Drosophila melanogaster to artificial selection of body weight and its phenotypic plasticity in two larval food environments. Evolution 45:1909-1923. 
Jasienski, M., and F. A. Bazzaz. 1999. The fallacy of ratios and the testability of models in biology. Oikos 84:321-326.

Jinks, J. L., N. E. M. Jayasekara, and H. Boughey. 1977. Joint selection for both extremes of mean performance and of sensitivity to a macroenvironmental variable. II. Single seed descent. Heredity 39:345-355.

Kindred, B. 1965. Selection for temperature sensitivity in scute Drosophila. Genetics 52:723-728.

Klimeš, L., J. Kliměsv́a R. Hendriks, and J. van Groenendael. 1997. Clonal plant architecture: a comparative analysis of form and function. Pp. 1-29 in H. de Kroon and J. van Groenendael, eds. The ecology and evolution of clonal plants. Backhuys Publishers, Leiden.

Lande, R., and S. J. Arnold. 1983. The measurement of selection on correlated characters. Evolution 37:1210-1226.

Littell, R. C., G. A. Milliken, W. W. Stroup, and R. D. Wolfinger. 1996. SAS system for mixed models. SAS Institute, Cary, NC.

McLellan, A. J., D. Prati, O. Kaltz, and B. Schmid. 1997. Structure and analysis of phenotypic and genetic variation in clonal plants. Pp. 185-210 in H. de Kroon and J. van Groenendael, eds. The ecology and evolution of clonal plants. Backhuys Publishers, Leiden.

Meyer, A. H., and B. Schmid. 1999. Experimental demography of the old-field perennial Solidago altissima: the dynamics of the shoot population. J. Ecol. 87:17-27.

Morrell, C. H. 1998. Likelihood ratio testing of variance components in the linear mixed-effects model using restricted maximum likelihood. Biometrics 54:1560-1568.

Ogden, J. 1974. The reproductive strategy of higher plants. II. The reproductive strategy of Tussilago farfara L. J. Ecol. 62: 291-324

Olivieri, I., Y. Michalakis, and P. H. Gouyon. 1995. Metapopulation genetics and the evolution of dispersal. Am. Nat. 146:202-228.

Patterson, H. D., and R. Thompson. 1971. Recovery of inter-block information when block sizes are unequal. Biometrika 58: 545-554.

Payne, R. W., P. W. Lane, P. G. N. Digby, S. A. Harding, P. K. Leech, G. W. Morgan, A. D. Todd, R. Thompson, G. Tunnicliffe Wilson, S. J. Welham, and R. P. White. 1993. Genstat 5, release 3, reference manual. Clarendon Press, Oxford, U.K.

Piquot, Y., D. Petit, M. Valero, J. Cuguen, P. de Laguerie, and P. Vernet. 1998. Variation in sexual and asexual reproduction among young and old populations of the perennial macrophyte Sparganium erectum. Oikos 82:139-148.

Prati, D., and M. Peintinger. 2000. Biological flora of central Europe: Ranunculus reptans L. Flora 195:135-145.

Prati, D., and B. Schmid. 2000. Genetic differentiation of life-history traits within populations of the clonal plant Ranunculus reptans. Oikos 90:442-456.

Roff, D. A. 1996. The evolution of genetic correlations: an analysis of patterns. Evolution 50:1392-1403.

Ronsheim, M. L., and J. D. Bever. 2000. Genetic variation and evolutionary trade-offs for sexual and asexual reproductive modes in Allium vineale (Liliaceae). Am. J. Bot. 87:1769-1777.

Sackville Hamilton, N. R., B. Schmid, and J. L. Harper. 1987. Life- history concepts and the population biology of clonal organisms. Proc. R. Soc. Lond. 232:35-57.

Salisbury, E. J. 1942. The reproductive capacity of plants: studies in quantitative biology. G. Bell and Sons, London.

Scheiner, S. M. 1993. Genetics and evolution of phenotypic plasticity. Annu. Rev. Ecol. Syst. 24:35-68.

Scheiner, S. M., and R. F. Lyman. 1991. The genetics of phenotypic plasticity. II. Response to selection. J. Evol. Biol. 4:23-50.

Schmid, B. 1990. Some ecological and evolutionary consequences of modular organization and clonal growth in plants. Evol. Trends Plants 4:25-34.

Schmid, B., and J. Weiner. 1993. Plastic relationships between reproductive and vegetative mass in Solidago altissima. Evolution 47:61-74.

Sebens, K. P. 1987. The ecology of indeterminate growth in animals. Annu. Rev. Ecol. Syst. 18:371-401.

Silvertown, J. W. 1983. Why are biennials sometimes not so few? Am. Nat. 121:448-453.

Stearns, S. C. 1992. The evolution of life-histories. Oxford Univ. Press, Oxford, U.K.

Stöcklin, J. 1999. Differences in life history traits of related Epilobium species: clonality, seed size and seed number. Folia Geobot. 34:7-18.

Thompson, S. R., and S. Kauffman Rook. 1988. Lack of a correlated response to canalizing selection in Drosophila melanogaster. J. Hered. 79:385-386.

Tuomi, J., and T. Vuorisalo. 1989. What are the units of selection in modular organisms? Oikos 54:227-233.

van Kleunen, M., and M. Fischer. 2001. Adaptive evolution of plastic foraging responses in a clonal plant. Ecology 83: 3309-3319.

van Kleunen, M., M. Fischer, and B. Schmid. 2000a. Costs of plasticity in foraging characteristics of the clonal plant Ranunculus reptans. Evolution 54:1947-1955.

- 2000b. Clonal integration in Ranunculus reptans: By-product or adaptation? J. Evol. Biol. 13:237-248.

- 2001. Effects of intraspecific competition on size variation and reproductive allocation in a clonal plant. Oikos 94:515-524.

Via, S. 1987. Genetic constraints on the evolution of phenotypic plasticity. Pp. 47-71. V. Loeschcke, ed. Genetic constraints on adaptive evolution. Springer-Verlag, Berlin.

Waddington, C. H. 1960. Experiments on canalizing selection. Genet. Res. 1:140-150.

Waddington, C. H., and E. Robertson. 1966. Selection for developmental canalisation. Genet. Res. 7:303-312.

Watson, M. A. 1984. Developmental constraints: effect on population growth and patterns of resource allocation in a clonal plant. Am. Nat. 123:411-426.

Weiner, J. 1988. The influence of competition on plant reproduction. Pp. 228-245 in J. Lovett Doust and L. Lovett Doust, eds. Plant reproductive ecology. Oxford Univ. Press, New York.

Williams, G. C. 1975. Sex and evolution. Princeton Univ. Press, Princeton, NJ.

Winkler, E., and M. Fischer. 2002. The role of vegetative and seed dispersal within habitats for optimal life histories of clonal plants: a simulation study. Evol. Ecol. 15:281-301.

Corresponding Editor: C. Eckert 